\title{
Global diarrhoea morbidity, weather and climate
}

\author{
Simon J. Lloyd, R. Sari Kovats*, Ben G. Armstrong \\ Department of Public Health and Health Policy, London School of Hygiene and Tropical Medicine, Keppel Street, \\ London WC1E 7HT, UK
}

\begin{abstract}
Diarrhoea rates are influenced by weather and climate; transmission can be affected by temperature and rainfall extremes, although few studies have quantified this effect. We undertook a global cross-sectional study of diarrhoea incidence in children under 5, drawing on studies published in the last $50 \mathrm{yr}$, and assessed the association with climate variables. Log-linear regression was used to quantify any association, controlling for the effects of age, socio-economic conditions and access to improved water and sanitation. We found a negative association between rainfall and diarrhoea rates, with a $4 \%$ increase in diarrhoea incidence (95\% confidence interval, $\mathrm{CI}: 1-7 \%, \mathrm{p}=0.02)$ for each $10 \mathrm{~mm} \mathrm{mo}^{-1}$ decrease in rainfall. Little evidence for association with temperature or climate type was found. Our result for rainfall is consistent with a similar study covering a smaller geographic region. Though biases cannot be excluded, the most likely mechanism is that low rainfall leads to water scarcity, which in turn leads to the use of unprotected water sources and reduces hygiene practices. In the future, greater numbers are expected to experience water scarcity, which may lead to more diarrhoea cases in some locations. This study lends support to programmes for hygiene and water and sanitation coverage, as well as lending support to actions to adapt to and mitigate climate change.
\end{abstract}

KEY WORDS: Diarrhoea $\cdot$ Weather $\cdot$ Climate $\cdot$ Temperature $\cdot$ Rainfall $\cdot$ Water scarcity $\cdot$ Developing countries $\cdot$ Climate change

\section{INTRODUCTION}

Diarrhoea morbidity is influenced by weather and climate variability (Victora et al. 1985, Salazar-Lindo et al. 1997, Checkley et al. 2000). Temperature affects pathogen survival (Kovats \& Tirado 2006), and watersupply contamination due to heavy rainfall has led to diarrhoea outbreaks (Curriero et al. 2001, Auld et al. 2004). Drought events and water scarcity may reduce hygiene practices and necessitate the use of unprotected water sources (Moran et al. 1997). It is suggested that climate change may increase the burden of diarrhoeal disease due to temperature increases (McMichael et al. 2004).

Studies of these associations are broadly of 2 types. Time-series studies examine the diarrhoea-weather relationship over a short timescale-for example, using weekly exposure and outcome data-and, in general, at a particular location. Cross-sectional stud- ies focus on longer-term averages for exposures and outcomes (e.g. annual averages), and can consider multiple sites. At these different scales, the apparent associations may be quite different. Information derived from such studies may serve distinct purposes: short-term associations, for example, may guide earlywarning systems, such as those for epidemic preparedness, while longer-term data may be more useful for physical infrastructure development. To date, the majority of research has been of the first type.

We know of only one multi-site cross-sectional study on diarrhoea and averaged weather conditions. In a study of 18 Pacific Islands using average annual weather conditions over a 10 yr period, Singh et al. (2001) found that hospitalisation for all-cause diarrhoea increased with decreasing water availability and increasing temperature. However, the relationships could not be quantified due to a lack of statistical power. 
In the present study we describe the influence of mean temperature and rainfall (over at least $1 \mathrm{yr}$ ) on diarrhoea incidence using data collated for 3 global burden of diarrhoeal disease reviews (Snyder \& Merson 1982, Bern et al. 1992, Kosek et al. 2003). The data are for all-cause diarrhoea and cover a global range of sites, predominately in low income countries. Our study concentrates on morbidity rates, which have remained fairly constant over the past decades despite reductions in mortality (Kosek et al. 2003). We test the primary hypothesis that climate factors, as measured by average weather conditions, are a determinant of diarrhoeal disease across sites globally, and also examine the association between diarrhoea and climate zone.

\section{METHODS}

We undertook a global cross-sectional study using age-specific, all-cause diarrhoea incidence rates in children under $5 \mathrm{yr}$ old as the primary outcome measures. Averaged weather conditions over the study period, as mean monthly rainfall and mean temperature, and climate type of a location were the exposures of interest. Information on confounders (national or local, as available) was obtained from global environmental datasets.

\subsection{Diarrhoea morbidity data}

The global burden of diarrhoeal disease was reviewed in 3 successive and related studies (Snyder \& Merson
1982, Bern et al. 1992, and Kosek et al. 2003). These studies focused on endemic rates of all-cause diarrhoea, and selected for review publications from between 1954 and 2000 according to a strict inclusion criteria: prospective, longitudinal studies, conducted in relatively stable populations over at least $12 \mathrm{mo}$, with morbidity surveillance at intervals of $\leq 2 \mathrm{wk}$. The reviews focused on children under 5 yr old living in low and middle income countries. In the present study we analyse the same population, as this group bears the majority of the burden of diarrhoeal disease (Black et al. 2003).

We assessed the morbidity papers included in the above reviews, excluding those that took place within an area of more than $100 \mathrm{~km}^{2}$, those not specifying the time-period of the study, and those not providing morbidity rates in age-aggregates useful for our analysis. All remaining studies were included. Study sites were categorised as rural, urban or slum settings, based on the description in the original study. On-line gazetteers (FRG 2006) were used to geo-reference the study sites and link the health outcome to environmental and socio-economic variables.

The 3 reviews made use of 62 morbidity studies. Of these, 2 were unavailable, 13 specified no relevant morbidity rates, and in 11, the location or time period of the study was insufficiently specified. We included the remaining 36 studies, and named this complete dataset, 'Dataset 1'. Because water, sanitation, and local income data were not available until 1985 (see below), we separately analysed the 15 studies conducted since 1985, as 'Dataset 2'. Fig. 1 shows the global distribution and climate zones of these studies; a summary of the datasets is given in Tables 1-4.

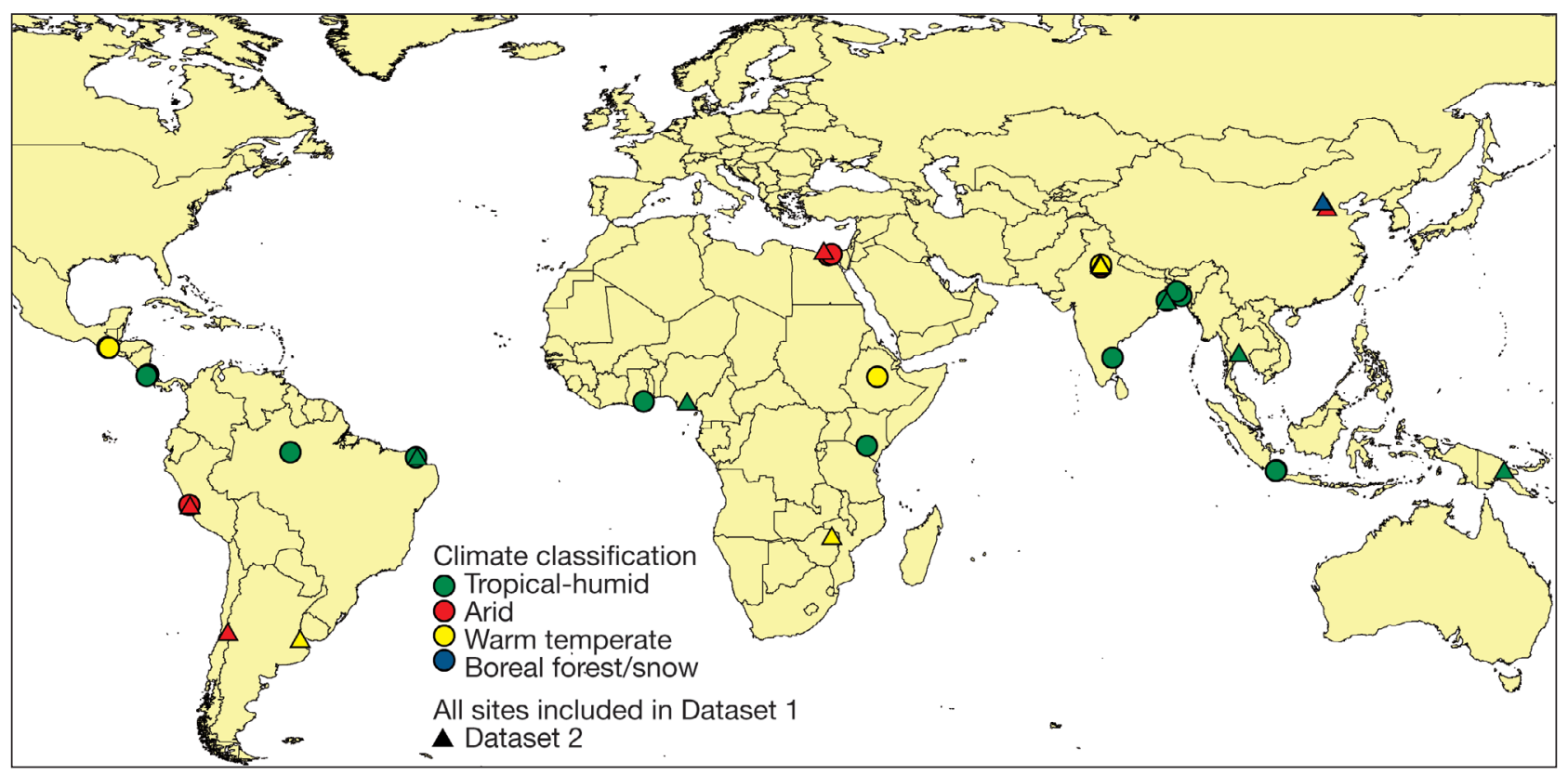

Fig. 1. Geographic distribution of study sites with Köppen-Geiger climate classification 
Table 1. Dataset 1. Median (range) GDP (gross domestic product; US\$ based on rate in 2000), number of morbidity studies, and decade they were commenced for study regions. For Tables 1-4, 'Region' refers to WHO defined regions; available at www.who.int/about/regions/en/index.html

\begin{tabular}{|c|c|c|c|c|c|c|c|}
\hline \multirow{2}{*}{ Region } & \multirow{2}{*}{$\begin{array}{l}\text { GDP per capita } \\
\text { (US\$) }\end{array}$} & \multirow{2}{*}{$\begin{array}{l}\text { No. of } \\
\text { studies }\end{array}$} & \multirow[b]{2}{*}{$1950 \mathrm{~s}$} & \multirow[b]{2}{*}{$1960 \mathrm{~s}$} & \multirow{2}{*}{$\begin{array}{c}\text { Commenced } \\
1970 \mathrm{~s}\end{array}$} & \multirow[b]{2}{*}{$1980 \mathrm{~s}$} & \multirow[b]{2}{*}{$1990 \mathrm{~s}$} \\
\hline & & & & & & & \\
\hline Global & $556(103-6546)$ & 36 & 3 & 6 & 7 & 18 & 2 \\
\hline Africa & $252(103-599)$ & 4 & - & - & 1 & 3 & - \\
\hline Americas & $2132(391-6545)$ & 14 & 2 & 2 & 3 & 7 & - \\
\hline E. Mediterranean & $949(548-1335)$ & 3 & 1 & - & - & 1 & 1 \\
\hline SE Asia & $241(185-1263)$ & 12 & - & 4 & 3 & 4 & 1 \\
\hline West Pacific & $388(326-564)$ & 3 & - & - & - & 3 & - \\
\hline
\end{tabular}

Table 2. Dataset 1. Median (range) diarrhoea rates for study regions. Rates are episodes per child yr

\begin{tabular}{|c|c|c|c|c|c|c|}
\hline \multirow{2}{*}{ Region } & \multicolumn{6}{|c|}{ - Age group } \\
\hline & $0-5 \mathrm{mo}$ & $6-11 \mathrm{mo}$ & $1 \mathrm{yr}$ & $2 \mathrm{yr}$ & $3 \mathrm{yr}$ & $4 \mathrm{yr}$ \\
\hline Global & $2.7(0.7-9.4)$ & $4.0(0.6-14.1)$ & $3.0(0.3-15.1)$ & $1.9(0.1-12.2)$ & $1.2(0.1-8.7)$ & $1.0(0.3-7.2)$ \\
\hline Africa & $2.7(1.8-2.7)$ & $4.8(3.3-5.0)$ & $2.6(2.4-5.0)$ & $1.6(0.9-3.8)$ & $0.7(0.7-3.0)$ & $0.6(0.4-2.8)$ \\
\hline Americas & $3.5(0.7-9.4)$ & $6.0(0.8-14.1)$ & $3.0(0.6-15.1)$ & $1.7(1.0-12.2)$ & $1.3(1.0-8.7)$ & $1.0(0.3-7.2)$ \\
\hline E. Mediterranean & $6.3(5.3-7.3)$ & $7.4(5.9-8.8)$ & $4.3(3.0-5.5)$ & $2.8(2.6-3.0)$ & 2.6 & 1.7 \\
\hline SE Asia & $2.2(0.9-4.9)$ & $3.1(0.6-7.3)$ & $2.8(0.3-6.0)$ & $1.8(0.1-5.5)$ & $0.9(0.1-1.7)$ & $0.6(0.4-1.6)$ \\
\hline West Pacific & 2.7 & $3.6(1.8-5.4)$ & $3.8(1.8-5.0)$ & $2.3(1.7-2.8)$ & $1.6(1.5-1.6)$ & $1.5(1.2-1.7)$ \\
\hline
\end{tabular}

Table 3. Dataset 1. Weather data and number of studies undertaken in each climate type (T: temperate; A: arid; Tr: tropical; $\mathrm{BF} / \mathrm{Sn}$ : boreal forest/snow) and setting (R: rural; U: urban; S: slum; M: mixed) for study regions. Weather data are median (range)

\begin{tabular}{|c|c|c|c|c|c|c|c|c|c|c|}
\hline \multirow[t]{2}{*}{ Region } & \multirow{2}{*}{$\begin{array}{l}\text { Rainfall } \\
\left(\mathrm{mm} \mathrm{mo}^{-1}\right)\end{array}$} & \multirow{2}{*}{$\begin{array}{c}\text { Temperature } \\
\left({ }^{\circ} \mathrm{C}\right)\end{array}$} & \multicolumn{4}{|c|}{ Climate type } & \multicolumn{4}{|c|}{- Setting -} \\
\hline & & & $\mathrm{T}$ & $\mathrm{A}$ & $\operatorname{Tr}$ & $\mathrm{BF} / \mathrm{Sn}$ & $\mathrm{R}$ & $\mathrm{U}$ & $\mathrm{S}$ & M \\
\hline Global & $90(0-331)$ & $25(7-28)$ & 9 & 8 & 18 & 1 & 18 & 12 & 5 & 1 \\
\hline Africa & $79(58-101)$ & $24(16-27)$ & 2 & - & 2 & - & 2 & 2 & - & - \\
\hline Americas & $122(0-331)$ & $24(13-27)$ & 4 & 3 & 7 & - & 7 & 4 & 3 & - \\
\hline E. Mediterranean & $3(2-6)$ & $21(20-21)$ & - & 3 & - & - & 3 & - & - & - \\
\hline SE Asia & $141(56-305)$ & $26(24-28)$ & 3 & 1 & 8 & - & 4 & 6 & 2 & - \\
\hline West Pacific & $39(37-165)$ & $13(7-21)$ & - & 1 & 1 & 1 & 2 & - & - & 1 \\
\hline
\end{tabular}

Table 4. Dataset 2. GCP (gross cell product; US\$ based on rate in 1995), number of studies in each region, and water and sanitation coverage for study regions. Except for studies, data are median (range). Rainfall and temperature were similar to Dataset $1-$ rainfall: $68(2-220) \mathrm{mm} \mathrm{mo}^{-1}$; temperature: $21(7-28){ }^{\circ} \mathrm{C}_{\text {; }}$ diarrhoea rates not shown

\begin{tabular}{|lcccc|}
\hline Region & $\begin{array}{c}\text { GCP } \\
\left(10^{6} \text { US\$) }\right.\end{array}$ & No. of studies & Water coverage & $\begin{array}{c}\text { Sanitation coverage } \\
(\%)\end{array}$ \\
\hline Global & $7968(171-27127)$ & 15 & $68(36-97)$ & $36(8-95)$ \\
Africa & $1606(367-2844)$ & 2 & $52(36-68)$ & $37(32-42)$ \\
Americas & $9221(988-27127)$ & 5 & $55(36-97)$ & $38(11-92)$ \\
E. Mediterranean & 3547 & 1 & 95 & 50 \\
SE Asia & $9647(3194-12155)$ & 4 & $73(70-86)$ & $11(8-95)$ \\
West Pacific & $7969(171-8662)$ & 3 & $60(58-60)$ & $10(8-54)$ \\
\hline
\end{tabular}

\subsection{Environmental and socio-economic data}

Climate data were obtained from the Integrated Database Information System (IDIS) (IWMI/CPWF 2006), which draws on the $0.5 \times 0.5^{\circ}$ resolution CRU TS 2.1 dataset (Mitchell \& Jones 2005). We used a geographic information system (GIS) to link the study sites to grid-cells and extracted the monthly time series for rainfall and temperature for each month over which the study was conducted. We then averaged the monthly figures to obtain the mean temperature and mean monthly rainfall during the study period. Sites were also categorised as tropical-humid, arid, warm temperate, or boreal forest and snow, based on the revised Köppen-Geiger climate classification (Beck et al. 2005, Kottek et al. 2006). 
In Dataset 1, we included data on gross domestic product (GDP) per capita. This was available at the national level from the World Bank Development Indicators database (World Bank 2006) and the average annual GDP per capita for the study period was calculated. A recently developed measure known as Gross Cell Product (GCP) (Nordhaus 2006) was used as a proxy for local socio-economic conditions for Dataset 2. This is an area-based equivalent of GDP and reflects the geographic intensity of economic activity at a resolution of $1 \times 1^{\circ}$ (approximately $100 \mathrm{~km}^{2}$ ). GCP was available for 1990, and we believed that this would provide a reasonable indication of socio-economic conditions for sites in Dataset 2, in which studies were conducted between 1985 and 2000.

Water and sanitation coverage (as proportion of the population with access to 'improved' sources or services, see www.wssinfo.org/en/122_definitions.html for definitions) data is compiled by the WHO/UNICEF Joint Monitoring Programme (JMP) (WHO \& UNICEF 2003), and is available at the national level, divided into rural and urban settings. Since the mid-1980s, the quality of this data has been significantly improved. Despite the lack of local level data, we considered the influence of water and sanitation to be of particular interest and included it in Dataset 2. We obtained the national coverage figures for both water and sanitation applicable to each study site from the JMP website (WHO \& UNICEF 2003), using the rural or urban estimates as appropriate. No estimates were available for slum settings; only 2 studies in Dataset 2 were in 'slums', and these were excluded from the main analysis for reasons that are outlined in Section 3.3. below.

\subsection{Statistical analysis}

We assessed the crude association between diarrhoea incidence and both rainfall and temperature. Using Dataset 1, we produced scatter-plots and calculated Pearson's correlation coefficients for the agebands $0-5$ and 6-11 mo, and for each year of age from 1-4 yr. Possible collinearity between rainfall and diarrhoea was assessed using correlation coefficients.

We then used linear regression to quantify the relationship between the logarithm of diarrhoea rate and the weather variables in both datasets. Variables were added to the models sequentially, beginning with age and socioeconomic conditions (as GDP per capita or GCP), followed by mean rainfall and temperature, and finally, the setting (rural, urban, slum, mixed) and water and sanitation coverage (for Dataset 2 only). Following this, we assessed influence of climate type (as Köppen-Geiger classification) using the same analysis but excluding the weather variables. To make the regression coefficients more easily interpretable, we exponentiated them so that they represent the incremental prevalence rate ratio per unit increase in the explanatory variable.

The regression analysis used age-specific rates, with multiple rates frequently abstracted for the same publication. This left our analysis prone to within-study clustering; to allow for this we used a mixed model with random study effects.

While all studies included in the datasets were conducted over a period of 1 yr or longer, many were not carried out over complete year periods. As a result, the averages for diarrhoea rates, rainfall, and temperature may have been skewed upwards or downwards, depending on the seasonal pattern during the partial year period. We carried out a sensitivity analysis which excluded covering partial year periods studies to account for this. Analyses were conducted using Stata v. 8 software.

\section{RESULTS}

\subsection{Crude associations}

Table 5 shows the Pearson's correlation coefficients for the crude relationship between the average weather variables and the logarithm of diarrhoea morbidity, and Fig. 2 shows example scatter plots. Rainfall appears to be negatively correlated with diarrhoea rates, with the strength varying by age-group (Table 5). One of the Brazilian sites, a slum with high diarrhoea prevalence and medium rainfall, was an outlier in this apparent relationship and in the distribution of diarrhoea rates, as seen at the top of Fig. 2a. Excluding this study from the correlation increased the strength of the crude association (Table 5). The association between temperature and diarrhoea was weaker and more variable (Table 5). The outlier study for the rainfall plots

Table 5. Dataset 1. Pearson's correlation coefficient by age group for association between log diarrhoea morbidity rate and climate parameters. Outlier: a study in an urban slum in Brazil, 1984-1986; All: includes outlier

\begin{tabular}{|lcccccc|}
\hline & \multicolumn{7}{c|}{ Age group } & \\
\cline { 2 - 7 } Parameter & $0-5 \mathrm{mo}$ & $6-11 \mathrm{mo}$ & $1 \mathrm{yr}$ & $2 \mathrm{yr}$ & $3 \mathrm{yr}$ & $4 \mathrm{yr}$ \\
\hline Mean rainfall & & & & & & \\
All & -0.51 & -0.36 & -0.14 & -0.06 & -0.14 & -0.08 \\
Excluding outlier & -0.61 & -0.45 & -0.22 & -0.15 & -0.31 & -0.28 \\
Mean temperature & & & & & & \\
All & 0.12 & 0.002 & -0.03 & -0.10 & -0.20 & 0.05 \\
Excluding outlier & 0.08 & -0.04 & -0.09 & -0.17 & -0.36 & -0.11 \\
\hline
\end{tabular}



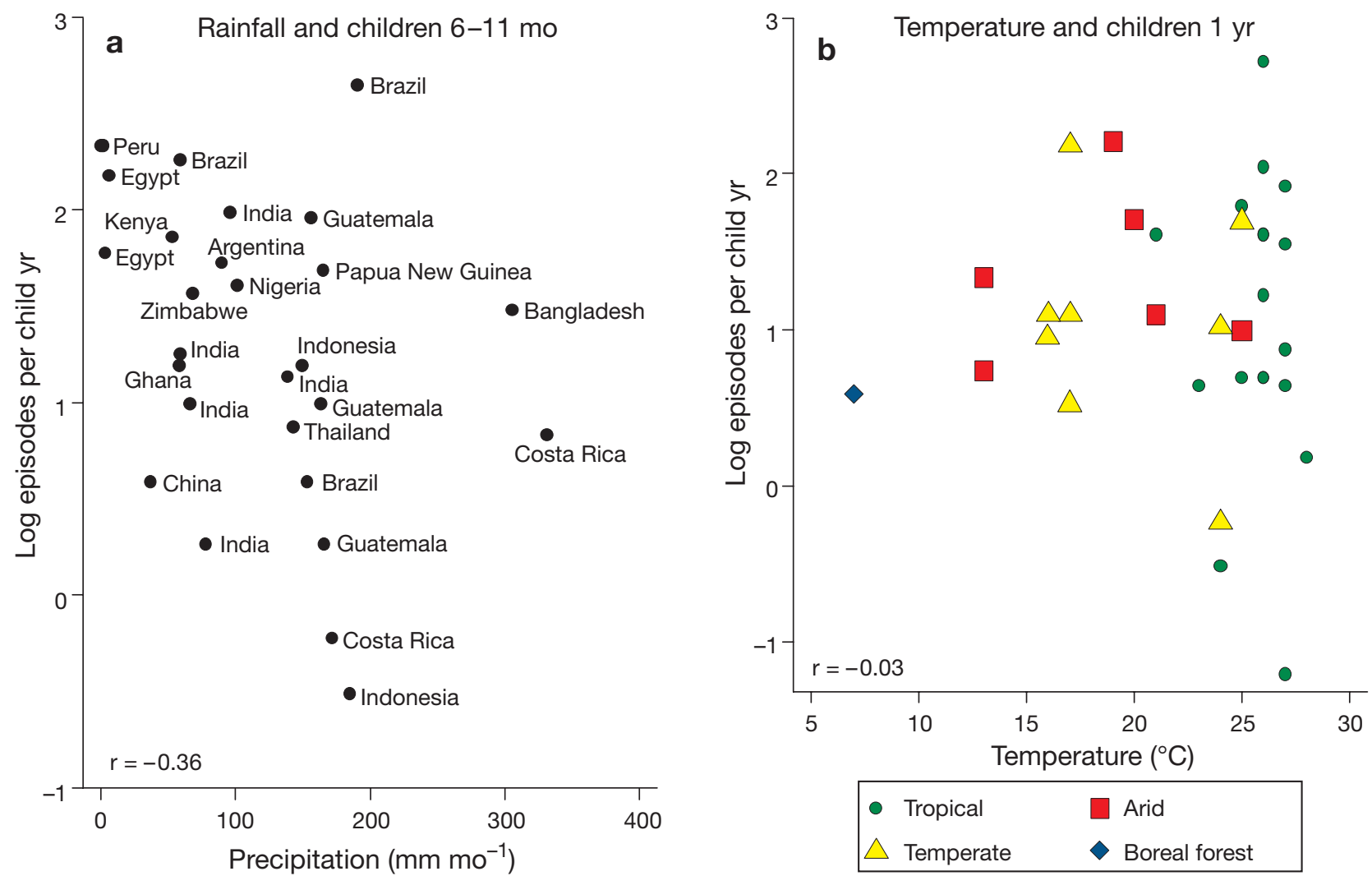

Fig. 2. Log diarrhoea-morbidity-rate scatterplots of (a) children aged 6-11 mo against mean rainfall, by country; and (b) children aged 1 yr against mean temperature, by climate classification

was also apparent in the temperature plots; rates were consistently high, and were double the nearest rate for 2 to 4 yr olds.

The correlation coefficients for the association between rainfall and temperature in Datasets 1 and 2 were 0.3 and 0.5 respectively. This level of collinearity need not exclude the simultaneous use of the variables in a regression model.

\subsection{Regression analysis of Dataset 1}

Using Dataset 1, we ran the regression models both including and excluding the outlier identified in the scatter plots. The results including the outlier are shown in Table 6. There was little evidence for association of either GDP or temperature with diarrhoea. Rainfall, however, was negatively associated with diarrhoea rates, with the final model suggesting that an increase in mean rainfall of $10 \mathrm{~mm} \mathrm{mo}^{-1}$ is associated with a $4 \%$ decrease in diarrhoea incidence (95\% CI: $1-7 \%, p=0.02)$. When rainfall was included in this model as a 3-level group variable, we found prevalence ratios (relative to 1 at $<50 \mathrm{~mm} \mathrm{mo}^{-1}$ ) of 0.55 at $50-149 \mathrm{~mm} \mathrm{mo}^{-1}$ and 0.39 at $\geq 150 \mathrm{~mm} \mathrm{mo}^{-1}$ (respec- tively: 95\% CI: $0.18-0.83, p=0.02$ and $95 \% \mathrm{CI}$ : $0.27-$ $1.13, \mathrm{p}=0.1$ ). The magnitude of the diarrhoea-rainfall relationship remained the same when the outlier study was excluded, however the strength of the evidence increased $(\mathrm{p}=0.004)$.

We found no strong evidence to suggest an influence due to rural, urban or slum setting, although low power was reflected in wide confidence intervals for these comparisons. Comparing grouped urban and slum sites to rural areas gave similar results.

The sensitivity analysis, which excluded 16 studies that included a part-year (out of 36 studies), gave a similar point estimate for the effect of rainfall to that in the final model (decrease in diarrhoea rate of $5 \%$ for each $10 \mathrm{~mm} \mathrm{mo}^{-1}$ of rainfall; $95 \% \mathrm{CI}$ : 3-8\%).

\subsection{Regression analysis of Dataset 2}

For Dataset 2, initial scatter-plots showed 2 studies with very high GCPs compared to the others. Both these studies were carried out in slums in Brazil (one being the outlier in Dataset 1), but had the highest GCPs in the dataset (US\$ 27000). As the nearest GCP to this was US\$15000, and the median was just 
Table 6. Dataset 1. Regression coefficients (95\% CI) for the association between diarrhoea morbidity rates and each variable. All models are adjusted for age group. Coefficients indicate change in diarrhoea rate (episodes per child yr) for each: 100 US\$ (based on US $\$$ rate in 2000) increase in gross domestic product (GDP) per capita; $10 \mathrm{~mm} \mathrm{mo}^{-1}$ increase in mean monthly rainfall; and $1^{\circ} \mathrm{C}$ increase in mean temperature

\begin{tabular}{|c|c|c|c|c|}
\hline Variable & Model 1 & Model 2 & Model 3 & Model 4 \\
\hline GDP & 1.01 (1.00-1.03) & $1.01(1.00-1.03)$ & $1.02(1.00-1.03)$ & $1.02(1.00-1.04)$ \\
\hline Rainfall & & $0.97(0.94-1.00)$ & $0.97(0.94-1.00)$ & $0.96(0.93-0.99)$ \\
\hline Temperature & & & $1.02(0.97-1.07)$ & $1.03(0.97-1.09)$ \\
\hline \multicolumn{5}{|l|}{ Setting } \\
\hline Rural & & & & 1 \\
\hline Urban & & & & $0.73(0.42-1.29)$ \\
\hline Slum & & & & $1.01(0.45-2.28)$ \\
\hline Mixed & & & & $1.63(0.38-6.93)$ \\
\hline
\end{tabular}

Table 7. Dataset 2. Regression coefficients (95\% CI) for association between diarrhoea morbidity rates and each variable, excluding both outlier studies. All models are adjusted for age group. Coefficients indicate the change in diarrhoea rate (episodes per child yr) for each: 1000 million US $\$$ (based on US $\$$ rate in 1995) increase in gross cell product (GCP); $10 \mathrm{~mm} \mathrm{mo}^{-1}$ increase in mean monthly rainfall; $1^{\circ} \mathrm{C}$ increase in mean temperature; and $10 \%$ increase in water or sanitation coverage

\begin{tabular}{|c|c|c|c|c|c|}
\hline Variable & Model 1 & Model 2 & Model 3 & Model 4 & Model 5 \\
\hline $\mathrm{GCP}$ & $0.98(0.91-1.06)$ & $0.97(0.90-1.06)$ & $0.96(0.88-1.05)$ & $0.95(0.88-1.03)$ & $0.95(0.81-1.13)$ \\
\hline Rainfall & & $0.96(0.89-1.02)$ & $0.93(0.85-1.02)$ & $0.93(0.86-1.01)$ & $0.93(0.85-1.02)$ \\
\hline Temperature & & & $1.04(0.96-1.11)$ & $1.04(0.97-1.10)$ & $1.04(0.96-1.12)$ \\
\hline Water coverage & & & & $0.91(0.77-1.08)$ & $0.91(0.69-1.20)$ \\
\hline Sanitation coverage & & & & & $1.00(0.77-1.30)$ \\
\hline
\end{tabular}

Table 8. Regression coefficients (95\% CI) (controlled for age group, GDP and setting) for association between diarrhoea morbidity and climate type (Köppen-Geiger classification)

\begin{tabular}{|lrcc|}
\hline Climate & $\mathrm{n}$ & Regression coefficient & $\mathrm{p}$ \\
\hline Temperate & 9 & 1 & \\
Arid & 8 & $1.68(0.82-3.46)$ & 0.16 \\
Tropical & 18 & $0.93(0.48-1.81)$ & 0.84 \\
Boreal forest/snow & 1 & $0.73(0.15-3.57)$ & 0.69 \\
\hline
\end{tabular}

US\$ 7968, we carried out an analysis including and excluding these studies.

The analysis including the outliers provided little evidence of an association between diarrhoea prevalence, the weather parameters, GCP, or water and sanitation coverage. The estimate for the effect of rainfall was a $3 \%$ reduction for each $10 \mathrm{~mm} \mathrm{mo}^{-1}$ increase in rainfall (95\% $\mathrm{CI}:-3 \%-10 \%, \mathrm{p}=0.3)$.

Table 7 shows the results when the outliers were excluded. Again, our analysis found little evidence for association between diarrhoea morbidity and GCP, temperature, or water and sanitation coverage. As in Dataset 1, there was an apparent negative association between rainfall and diarrhoea morbidity. The final model suggested a $7 \%$ fall in diarrhoea rates for each $10 \mathrm{~mm} \mathrm{mo}{ }^{-1}$ increase in mean rainfall; however, the
$95 \%$ CI ranged from a $15 \%$ decrease to a $2 \%$ increase $(p=0.13)$. Owing to the small size of this dataset, a sensitivity analysis was not attempted.

\subsection{Climate type and diarrhoea morbidity}

The regression coefficients for Köppen-Geiger classification as predictors of diarrhoea morbidity-controlled for age, GDP, and setting-are shown in Table 8. Arid regions had the highest diarrhoea rates after adjustment; the differences, however, were not statistically significant.

\section{DISCUSSION}

Our analysis suggests that low rainfall, over a period of at least a year, is a determinant of childhood diarrhoeal disease in low and middle income countries. We found rainfall has a negative linear relationship with diarrhoea rates, which concurs with Singh et al.'s (2001) cross-sectional study in the Pacific Islands; our study suggests this association may exist over globally dispersed sites. Such a finding is plausible, as precipitation is a major determinant of streamflow and ground water recharge, with low levels potentially leading to water scarcity (Ahmad et al. 2001). This may in turn 
lead people to use less protected water sources, and reduce hygiene behaviour, resulting in increased diarrhoea incidence (Moran et al. 1997).

Studies of the association between rainfall and diarrhoea over the short term (weekly or monthly) have found both low and high rainfall increase diarrhoea incidence (Curriero et al. 2001, Singh et al. 2001). Such studies have linked outbreaks to extreme rainfall events. These outbreaks, however, are likely to be short-lived, and following initial contamination, continued rainfall is likely to dilute any pathogens and restore water quality (Singh et al. 2001). Thus, extreme rainfall events may have a relatively limited influence on long-term diarrhoea rates. In contrast, low rainfall, and the possible water scarcity, may lead to increased diarrhoea for the whole dry period duration. This may explain why a U-shaped relationship is seen in time series studies of short-term associations, while ours found a linear relationship.

At present, almost a third of the global population (approximately 1.7 billion people) experience water stress, and this is expected to increase to 5 billion people by 2025 (Ahmad et al. 2001). Climate change is likely to aggravate this situation, perhaps contributing to $20 \%$ of the future increases in water scarcity (Ahern 2006). As our findings suggest diarrhoea morbidity increases with water scarcity, the large number of people projected to have limited access to water in the future may be particularly vulnerable to diarrhoea. Further, recent research suggests repeated episodes of dehydrating diarrhoea may have chronic effects, including impairing growth and cognitive ability (Guerrant et al. 2002), and hypertension (Davey Smith et al. 2006, Lawlor et al. 2006). That is, the effects of diarrhoea morbidity may extend well beyond the acute event. More widespread water scarcity in the future may, through increased diarrhoea, have far reaching consequences, including an impact on the growing burden of chronic disease in low- and middle-income countries.

Unexpectedly, we found no association between average temperature and diarrhoea morbidity. This contrasts with the positive associations found in studies of temperature as an annual average (Singh et al. 2001), and of short-term (monthly or weekly) temperature variability (Checkley et al. 2000, Lama et al. 2004). Pathogens respond differently to temperature, with bacteria and protozoa thriving in warm conditions and viruses generally peaking in the cooler seasons (Podewils et al. 2004). Our study considered all-cause diarrhoea in a broad range of sites, possibly having quite different pathogen profiles, and this may explain the lack of an association between diarrhoea and temperature. However, all study sites were in developing regions and bacteria and protozoa tend to dominate in these areas (O'Ryan et al. 2005). An alternative explanation is that the range of temperatures in the study sites, which were mostly in 'hot' areas, was too narrow to allow differences to be detected (median temperature: $24.5^{\circ} \mathrm{C}$; 25 th -75 th percentile: $19.5-26^{\circ} \mathrm{C}$ ). Finally, uncontrolled biases may have obscured an association.

In the present study, we used the most valid allcause diarrhoea morbidity rates that were available. However, ascertaining a case of diarrhoea is not rigorously objective, and the authors of the global burden of diarrhoeal disease reviews each noted that studies employed a number of case definitions, and that, to a degree, rates tended to increase with frequency of ascertainment and decrease with study size (Kosek et al. 2003). However, as it is unlikely that the resulting variations in estimates were associated with either rainfall or temperature, bias due to this limitation seems unlikely.

We found little evidence of association between the indicators of socio-economic development (GDP and GCP) and diarrhoea rates. As the geographical areas covered by studies included in this analysis were much smaller than countries, variables based on national estimates are of limited value. To partially overcome this, we used a measure with finer geographical resolution (GCP) in Dataset 2. GCP and GDP per capita were poorly correlated $(\mathrm{r}=0.14)$, confirming that they measure different things. However, although GCP measures income in an area considerably smaller than most countries, these areas are still large (around $100 \mathrm{~km}^{2}$ ), within which a variety of socio-economic conditions may be seen. The inclusion of areas of poverty surrounded by wealth may have obscured an association of GCP with diarrhoea rates in our study, although, eliminating the 2 studies that were most likely to suffer from such misclassification still failed to find an association.

The evident limitations of the available measures of economic deprivation and access to water and sanitation (only available at national level, split by urban/ rural area) could have biased the association between rainfall and diarrhoea, by residual confounding. Further, unaccounted-for population factors which may have influenced disease rates may have biased our results. Nevertheless, as with misclassification in ascertainment of diarrhoea discussed above, there seems no particular reason to suspect that these variables (or other unmeasured risk factors) would be associated with rainfall, so substantial bias does not seem likely.

Finally, as for temperature, it is possible that a lack of association between diarrhoea and GDP or GCP, and similarly, with water and sanitation provision, was due to the limited range of these variables. The majority of study sites were low-income, and water and sanitation coverage was broadly similar. Despite this possibility, 
the sites included in the study are representative in terms of climate and development of areas bearing the greatest burden of diarrhoea, meaning the apparent influence of rainfall is important.

\section{CONCLUSIONS}

We found that low rainfall may be associated with increased diarrhoea morbidity in children, most likely due to resulting water scarcity. Thus the impacts of low rainfall on diarrhoeal disease may be avoided by ensuring safe and reliable water and sanitation infrastructure. Our findings add support to efforts to improve global water and sanitation coverage, and may suggest one means of identifying the most vulnerable populations. Quantity of available water is strongly related to diarrhoea rates, and disease may be prevented by increasing access and/or improving microbial quality (Clasen et al. 2007). Additionally, the potential for climate change to increase water scarcity means this study adds some support to the need for mitigation and adaptation measures.

The vast majority of the burden of diarrhoeal disease, and the impact of water scarcity on diarrhoea, is, and is likely to continue to be, experienced by young children in developing countries. Addressing this issue will prevent further widening of global health inequalities.

Acknowledgements. This research was funded by the European Commission, as part of the ENSEMBLES project (contract number GOCE-CT-2003-505539). Thanks to K. Lachowycz for assistance with climate data and geo-referencing, R. Tol for G-Econ data, and K. Bostoen for advice on water and sanitation data.

\section{LITERATURE CITED}

Ahern M (2006) Water and health: a world water crisis? In: Wilkinson P (ed) Environmental epidemiology. Open University Press, Maidenhead, p 109-124

Ahmad QK, Anisimov O, Arnell NW, Brown S and 61 others (2001) Summary for policymakers. In: McCarthy J, Canziani OF, Leary NA, Dokken DJ, White KS (eds) Climate change 2001: impacts, adaptation, vulnerability. Contribution of Working Group II to the Third Assessment Report of the Intergovernmental Panel on Climate Change. Cambridge University Press, Cambridge. [see http://www.cambridge.org/uk/catalogue/catalogue.asp?isbn=052101500]

Auld H, MacIver D, Klaassen J (2004) Heavy rainfall and waterborne disease outbreaks: the Walkerton example. J Toxicol Environ Health A 67:1879-1887

Beck C, Grieser J, Kottek M (2005) Characterizing global climate change by means of the Köppen climate classification. Klimastatusbericht:139-149

Bern C, Martines J, de Zoysa I, Glass RI (1992) The magnitude of the global problem of diarrhoeal disease: a ten year update. Bull WHO 70:705-714
Black RE, Morris SS, Bryce J (2003) Where and why are 10 million children dying every year? Lancet 361:2226-2234

Checkley W, Epstein LD, Gilman RH, Figueroa D, Cama RI, Patz JA, Black RE (2000) Effect of El Nino and ambient temperature on hospital admissions for diarrhoeal diseases in Peruvian children. Lancet 355:442-450

Clasen T, Schmidt W, Rabie T, Roberts I, Cairncross S (2007) Interventions to improve water quality for preventing diarrhoea: systematic review and meta-analysis. Br Med J 334:782

Curriero FC, Patz JA, Rose JB, Lele S (2001) The association between extreme precipitation and waterborne disease outbreaks in the United States, 1948-1994. Am J Publ Health 91:1194-1199

Davey Smith G, Leary S, Ness A, ALSPAC Study Team (2006) Could dehydration in infancy lead to high blood pressure? J Epidemiol Community Health 60:142-143

FRG (Falling Rain Genomic Inc.) (2006) Global Gazetteer, Version 2.1. Available at: www.fallingrain.com/world/ index.html. Accessed: August 18, 2006

Guerrant RL, Kosek M, Lima AA, Lorntz B, Guyatt HL (2002) Updating the DALYs for diarrhoeal disease. Trends Parasitol 18:191-193

IWMI/CPWF (International Water Management Institute, Challenge Programme on Water and Food) (2006) Integrated Database Information System. Available at: www. iwmi.cgiar.org. Accessed: August 18, 2006

Kosek M, Bern C, Guerrant RL (2003) The global burden of diarrhoeal disease, as estimated from studies published between 1992 and 2000. Bull WHO 81:197-204

Kottek M, Grieser J, Beck C, Rudolf B, Rubel F (2006) World map of the Köppen-Geiger climate classification updated. Meteorol Z 15:259-263

Kovats RS, Tirado C (2006) Climate, weather and enteric disease. In: Menne B, Ebi KL (eds) Climate change and adaptation strategies for human health. Steinkopff Verlag, Darmstadt, p 270-295

Lama JR, Seas CR, Leon-Barua R, Gotuzzo E, Sack RB (2004) Environmental temperature, cholera, and acute diarrhoea in adults in Lima, Peru. J Health Popul Nutr 22:399-403

Lawlor DA, Smith GD, Mitchell R, Ebrahim S (2006) Adult blood pressure and climate conditions in infancy: a test of the hypothesis that dehydration in infancy is associated with higher adult blood pressure. Am J Epidemiol 163:608-614

McMichael A, Campbell-Lendrum D, Kovats RS, Edwards S and 8 others (2004) Global climate change. In: Ezzati M, Lopez AD, Rodgers A, Murray CJ (eds) Comparative quantification of health risks: global and regional burden of disease due to selected major risk factors, Vol 2. WHO, Geneva, p 1543-1649

Mitchell TD, Jones PD (2005) An improved method of constructing a database of monthly climate observations and associated high-resolution grids. Int $\mathrm{J}$ Climatol 25: $693-712$

Moran P, Nhandara C, Hove I, Charimari L, Katito C, Bradley M, Williams MA (1997) Contamination of traditional drinking water sources during a period of extreme drought in the Zvimba communal lands, Zimbabwe. Cent Afr J Med 43:316-321

Nordhaus W (2006) G-econ project. Available at: gecon.yale. edu. Accessed: August 18, 2006

O'Ryan M, Prado V, Pickering LK (2005) A millennium update on pediatric diarrheal illness in the developing world. Semin Pediatr Infect Dis 16:125-136

Podewils LJ, Mintz ED, Nataro JP, Parashar UD (2004) Acute, infectious diarrhea among children in developing countries. Semin Pediatr Infect Dis 15:155-168 
Salazar-Lindo E, Pinell-Salles P, Maruy A, Chea-Woo E (1997) El Nino and diarrhoea and dehydration in Lima, Peru. Lancet 350:1597-1598

Singh RB, Hales S, de Wet N, Raj R, Hearnden M, Weinstein $P$ (2001) The influence of climate variation and change on diarrheal disease in the Pacific Islands. Environ Health Perspect 109:155-159

Snyder JD, Merson MH (1982) The magnitude of the global problem of acute diarrhoeal disease: a review of active surveillance data. Bull WHO 60:605-613

Editorial responsibility: Mauricio Lima, Santiago, Chile
Victora CG, Vaughan JP, Barros FC (1985) The seasonality of infant deaths due to diarrheal and respiratory diseases in southern Brazil, 1974-1978. Bull Pan Am Health Organ 19:29-39

WHO, UNICEF (2003) Joint Monitoring Programme for Water Supply and Sanitation. Available at: www.wssinfo.org/ en/welcome.html. Accessed: August 18, 2006

World Bank (2006) World Bank Quick Query Database. Available at: http://devdata.wordbank.org/query. Accessed: August 18, 2006

Submitted: January 25, 2007; Accepted: June 12, 2007 Proofs received from author(s): July 11, 2007 